\title{
BMJ Open Outcomes of hyperglycaemia in pregnancy in Africa: systematic review study protocol
}

Ezekiel Musa (i) , ${ }^{1,2}$ Tawanda Chivese (D) , ${ }^{3}$ Mahmoud Werfalli, ${ }^{4}$ Mushi Matjila, ${ }^{5}$ Shane A Norris, ${ }^{6}$ Naomi Levittt ${ }^{1,2}$

To cite: Musa E, Chivese T, Werfalli M, et al. Outcomes of hyperglycaemia in pregnancy in Africa: systematic review study protocol. BMJ Open 2021;11:e040921. doi:10.1136/ bmjopen-2020-040921

- Prepublication history for this paper is available online. To view these files, please visit the journal online (http://dx.doi. org/10.1136/bmjopen-2020040921).

Received 26 May 2020 Revised 24 December 2020 Accepted 05 January 2021
Check for updates

(C) Author(s) (or their employer(s)) 2021. Re-use permitted under CC BY-NC. No commercial re-use. See rights and permissions. Published by BMJ.

For numbered affiliations see end of article.

Correspondence to

Dr Naomi Levitt;

naomi.levitt@uct.ac.za

\section{ABSTRACT}

Introduction The prevalence of diabetes mellitus globally has increased considerably over the past decades with a resultant increase in the incidence of diabetescomplicated pregnancies. Hyperglycaemia in pregnancy is the most common metabolic complication encountered during pregnancy and is associated with adverse maternal and fetal outcomes. This systematic review aims to examine maternal, fetal, neonatal, childhood and longterm maternal outcomes of hyperglycaemia in pregnancy in Africa.

Methods and analysis A systematic review of all studies that investigated hyperglycaemia in pregnancy outcomes, carried out in Africa from 1998 to 2019. A comprehensive search of all published articles indexed in PubMed-MEDLINE, Cochrane Library, Scopus, CINAHL (EBSCOhost), Embase and Web of Science databases will be performed. Studies will be screened for eligibility by title, abstract and full text in duplicate by two independent reviewers. For data where meta-analysis is not possible, narrative analysis will be carried out using themes from data. For data where meta-analysis is possible, random effects meta-analysis will be conducted. This systematic review will be reported according to the Meta-analyses of Observational Studies in Epidemiology.

Ethics and dissemination Ethical approval is not required for this study considering this is a systematic review protocol that uses only published data. The findings of this study will be disseminated through peer-reviewed publications and conference presentations.

PROSPERO registration number CRD42020184573.

\section{INTRODUCTION}

While the number of people with diabetes globally has considerably increased over the past few decades, so too has the incidence of diabetes-complicated pregnancies. ${ }^{1}$ Hyperglycaemia in pregnancy (HIP), defined by the WHO in 2014, includes diabetes first detected at any time during pregnancy, subclassified as overt diabetes in pregnancy (DIP) and gestational diabetes mellitus (GDM) and pre-existing diabetes. ${ }^{2}$ HIP is regarded as the most common metabolic complication encountered during pregnancy. ${ }^{2}$ This is in part driven by the rising prevalence of type 2

\section{Strengths and limitations of this study}

The proposed study will provide updated knowledge on the prevalence of maternal, fetal, neonatal, childhood and long-term maternal and offspring outcomes of hyperglycaemia in pregnancy in Africa.

- The Burden of Disease Review Manager developed by the South African Medical Research Council will be used for extraction and recording of research data by two independent reviewers.

- The protocol adheres to the Meta-analyses of Observational Studies in Epidemiology reporting guideline.

- Meta-analysis may not be possible for certain outcomes due to a limited number of eligible studies.

diabetes mellitus (T2DM) and its risk factors and changing criteria for GDM. ${ }^{3-6}$ The International Diabetes Federation (IDF) in 2013 reported that globally, $16.9 \%$ (21.4 million) of live births in women of reproductive age (16-49 years) were complicated by HIP, with known or previously undiagnosed type 1 and 2 diabetes accounting for about $16 \%{ }^{1}$

Although the extent of the burden of HIP in Africa is not known, a recent systematic review reported that the pooled prevalence of T2DM in women of childbearing age on the continent was $7.2 \%{ }^{7}$ Further, a systematic review of the prevalence of GDM in Africa found a pooled prevalence of $13.6 \%$ with the prevalence in sub-Saharan Africa (SSA) reported at $9 \%$ and $14.8 \%$ by different groups. ${ }^{89}$

HIP is associated with adverse maternal and fetal outcomes during pregnancy. These include increased caesarean delivery rate, pre-eclampsia, difficult labour, macrosomia, shoulder dystocia, perinatal mortality, neonatal hypoglycaemia and congenital malformations. ${ }^{10-13}$ In addition, there are accumulating global data of the long-term impact of GDM on maternal health, childhood adiposity and glucose tolerance. ${ }^{13-15}$ 
There are isolated reports on pregnancy outcomes of women with pregestational diabetes in Africa. ${ }^{16-18}$ In a systematic review of the burden, risk factors and outcomes of GDM pregnancies in SSA, Natamba et al found that up to 2018 , six studies reported on pregnancy-related outcomes. ${ }^{9}$ They found that GDM was associated with an increased risk of macrosomia (RR 2.19, 95\% CI 1.08 to 4.43 ) and a non-significant risk of caesarean delivery. ${ }^{9}$

The aim of this systematic review is to examine the maternal, fetal, neonatal, childhood and long-term maternal and offspring outcomes of HIP in Africa, a continent where many countries are experiencing an increasing prevalence of non-communicable diseases (NCDs), while burdens from infectious diseases continue to be high and health systems remain weak. The data obtained will provide useful information for health systems planning and strengthening.

The specific objectives are:

1. Primary: to estimate the prevalence of the following outcomes from HIP in Africa:

A. Maternal outcomes: pre-eclampsia, caesarean delivery rate.

B. Fetal/neonatal outcomes: fetal macrosomia, congenital anomalies, intrauterine fetal death, shoulder dystocia, neonatal morbidity (hypoglycaemia, sepsis, respiratory immaturity, jaundice, neonatal intensive care unit admission and duration of neonatal hospital stay), perinatal mortality (early neonatal death (ENND) and stillbirth (SB) rates).

2. Secondary: to estimate the prevalence of the following outcomes from HIP in Africa:

A. Maternal outcomes: miscarriage, preterm birth, antepartum and puerperal sepsis, gestational hypertension.

B. Fetal/neonatal outcomes: birth trauma, small for gestational age babies, infant deaths.

C. Long-term maternal outcomes: type 2 diabetes, metabolic syndrome, cardiovascular disease risk factors.

D. Offspring outcomes: childhood overweight and obesity, and childhood pre-diabetes and diabetes as well as the prevalence of NCDs in adulthood (hypertension, diabetes, coronary heart disease, peripheral artery disease and cerebrovascular accidents).

\section{METHODS AND ANALYSIS}

\section{Design}

This research will use a systematic review of all literature published during the period 1998-2019. A meta-analysis will be carried out where sufficient data with low heterogeneity are available.

\section{Inclusion criteria}

Studies reporting the outcomes of HIP among women resident in Africa and published between 1998 and 2019 will be included as current criteria for the diagnosis of diabetes have been widely accepted since 1998. Participants will be included irrespective of their age, ethnicity, educational and socioeconomic status, gestational age and study setting. Diagnosis of pregestational diabetes (type 1 or type 2 diabetes) and GDM will be defined according to WHO 1999/2013, the American diabetes Association (ADA) and IADPSG diagnostic criteria or definition. ${ }^{19-22}$

All published and unpublished cohort or cross-sectional studies and baseline data from randomised controlled trials (RCT) conducted in Africa reporting on the prevalence of the outcomes of HIP will be included. Also, published multicentre studies where African patients were involved will be included.

\section{Settings}

Hospital and community-based studies.

\section{Exclusion criteria}

A. Studies not performed in humans.

B. Studies not carried out in Africa.

C. Studies in migrant African populations in regions other than Africa.

D. Reviews, commentaries, editorials, letters and studies without primary data or explicit description of methods, or both.

E. Qualitative studies.

\section{Definition of outcomes}

Definitions for key outcomes, where different criteria exist, are given below.

1. Pre-eclampsia defined as a multisystem progressive disorder characterised by the new onset of hypertension and proteinuria or the new onset of hypertension and significant end-organ dysfunction with or without proteinuria in the last half of pregnancy or post partum. ${ }^{23}$ The end evidence of organ dysfunction includes: (1) proteinuria $\geq 0.3 \mathrm{~g}$ in a 24 -hour urine specimen or protein/creatinine ratio $\geq 0.3(\mathrm{mg} / \mathrm{mg})(30 \mathrm{mg} / \mathrm{mmol})$ in a random urine specimen or dipstick $\geq 2+$ if a quantitative measurement is unavailable, (2) renal insufficiency—serum creatinine $>1.1 \mathrm{mg} / \mathrm{dL}(97.2 \mu \mathrm{mol} / \mathrm{L})$ or doubling of the creatinine concentration in the absence of other renal disease, (3) liver involvementliver transaminases at least twice the upper limit of the normal concentrations for the local laboratory, (4) neurological complications-new-onset and persistent headache not accounted by alternative diagnoses and not responding to usual doses of analgesics, and visual symptoms (blurred vision, flashing lights or sparks, scotomata), and (5) thrombocytopenia-platelet count $<100 \times 10^{\wedge} 9 / \mathrm{L}^{23}{ }^{24}$

2. Primary caesarean delivery defined as the delivery by caesarean section for the first time. ${ }^{25}$

3. Congenital malformations will be defined as any single or multiple defects of the morphogenesis of organs or body regions identifiable at birth or during the intrauterine life. ${ }^{26}$

4. Spontaneous abortion/miscarriage will be defined as any pregnancy loss before the 28th week of gestation 
(this is relevant for low and middle-income countries (LMIC) setting) or loss of fetus less than $500 \mathrm{~g}^{27-29}$

5. Perinatal mortality will be defined as a combination of SBs and ENND (death before 7 days) (this is relevant for an LMIC setting). ${ }^{28} 30$

\section{Patient and public involvement}

As no participant recruitment will be necessary, patients will not be involved in the design of this study protocol.

\section{Search strategy for identification of relevant studies}

A sensitive search strategy will be applied using the updated African search filter to retrieve published studies of outcomes of DIP. Search articles published in English and indexed in PubMed-MEDLINE, Cochrane Library, Scopus, CINAHL (EBSCOhost), Embase and Web of Science databases will be retrieved from the start of each database until a present date to capture all relevant studies. Our search strategy will use Medical Subject Headings and free text. Unpublished literature will be sought from experts in the field while grey literature such as reports will also be reviewed for relevant information from other organisational websites such as WHO, IDF, Google Scholar and Pan African Clinical Trials Registry. The support of an experienced librarian will be sought for the validation and cross-examination of our search strategy.

\section{Study selection for this review}

Two reviewers (EM, TC) will independently screen titles and abstracts of articles to identify eligible studies. Any discrepancies and doubts will be addressed via group discussion and consultation among the two reviewers (EM, TC).

Disagreements will be resolved through discussion and when needed there will be arbitration by a third reviewer (MW). Copies of eligible full texts will be retrieved and analysed by the two reviewers (EM, TC). Where necessary, further information will be sought from the authors of studies. Reasons for excluding articles will be recorded.

\section{Data extraction}

The Burden of Disease (BOD) Review Manager developed by the South African Medical Research Council will be used for extraction and recording of research data by two independent reviewers (EM, TC).$^{31}$ The data to be extracted include study details-publication date, title of study, study design, period and objective of the study; study population - country of study, study setting and sample size; and response rate, case definition of outcomes reported in the study and study population characteristics. After the data extraction is completed, the two reviewers will address any identified difference or consult a third reviewer (MW). Where there is missing information, the corresponding author of the study will be contacted to request the missing information. No response to a maximum of three emails over 2 weeks sent to the corresponding author to request for additional information will lead to exclusion of the study. For studies appearing in more than one published article, we will consider the most recent, comprehensive and with the largest sample size. For surveys appearing in one article with multiple surveys conducted at different time points, we shall treat each survey as a separate study. For multinational studies, data will be separated to show the estimate at country level.

\section{Risk of bias assessment}

Risk of bias and quality of study will be identified independently by two reviewers using a checklist for observational studies adapted from the risk of bias tool for population-based studies and the Newcastle-Ottawa Scale for assessing the quality of non-randomised studies with standardisation in the BOD Review Manager, while Cochrane risk of bias tool will be used for RCTs. ${ }^{32} 33$ External and internal validity will be assessed with discrepancies among reviewers over the risk of bias resolved by consensus and an additional reviewer when the need arises.

\section{Data synthesis and heterogeneity assessment}

Crude numerators and denominators from the individual studies will be used to recalculate the study-specific prevalence. Prevalence estimates will be summarised by geographic regions and by outcomes. A meta-analysis will be performed on variables that are similar across the included studies.

For the meta-analysis, proportions will be stabilised using the double arcsine transformation, ${ }^{34}$ and then a random effects meta-analysis will be performed ${ }^{35}$ to determine the pooled estimate of the prevalences. Heterogeneity will be explored using Cochrane's $Q$ and quantified by $\mathrm{I}^{2}$ statistics. ${ }^{36}$ Subgroup analyses will be performed based on the following: patient characteristics (age categories, sex, education level, socioeconomic status). The presence of publication bias will be assessed using Egger's test and funnel plots. ${ }^{37} \mathrm{P}$ value $<0.10$ on the Egger's test will be considered to be statistically significant for publication bias. ${ }^{37}$ Inter-rater agreements between the researchers involved in study selection and those involved in the identification of risk of bias will be assessed using $\kappa$ Cohen's coefficient. ${ }^{38}$ All analyses will be performed using 'Metaprop' routine using Stata V.15. ${ }^{39}$ Results will be reported as proportions with corresponding $95 \%$ CIs.

\section{Review reporting}

Meta-analyses of Observational Studies in Epidemiology (MOOSE) will be used for reporting this systematic review. ${ }^{40}$ The guideline for reporting systematic reviews of healthcare intervention will constitute a MOOSE checklist.

\section{ETHICS AND DISSEMINATION}

Ethical approval will not be required for this study, as this is a systematic review protocol that uses only published data and the study findings will be shared 
with the public either through peer-reviewed publication or abstract presentation at conferences and possible submission to the relevant regional/global health policymaking bodies.

\section{Author affiliations}

${ }^{1}$ Division of Endocrinology, Department of Medicine, University of Cape Town, Cape Town, Western Cape, South Africa

${ }^{2}$ Chronic Disease Initiative for Africa, Department of Medicine, University of Cape Town, Cape Town, South Africa

${ }^{3}$ Department of Population Medicine, College of Medicine, QU Health, Qatar University, Doha, Ad Dawhah, Qatar

${ }^{4}$ Department of Family and Community Medicine, Faculty of Medicine, University of Benghazi, Benghazi, Libya

${ }^{5}$ Department of Obstetrics and Gynaecology, University of Cape Town, Cape Town, South Africa

${ }^{6} \mathrm{MRC} /$ Wits Developmental Pathways for Health Research Unit, Department of Paediatrics, University of the Witwatersrand, Johannesburg, South Africa

\section{Twitter Tawanda Chivese @TChivese}

Contributors EM and NL designed the study. EM wrote the first manuscript of the review. EM, TC, MW, MM, SAN and NL revised the review. All authors read and approved the final manuscript.

Funding The authors have not declared a specific grant for this research from any funding agency in the public, commercial or not-for-profit sectors.

Competing interests None declared.

Patient and public involvement Patients and/or the public were not involved in the design, or conduct, or reporting, or dissemination plans of this research.

Patient consent for publication Not required.

Provenance and peer review Not commissioned; externally peer reviewed.

Open access This is an open access article distributed in accordance with the Creative Commons Attribution Non Commercial (CC BY-NC 4.0) license, which permits others to distribute, remix, adapt, build upon this work non-commercially, and license their derivative works on different terms, provided the original work is properly cited, appropriate credit is given, any changes made indicated, and the use is non-commercial. See: http://creativecommons.org/licenses/by-nc/4.0/.

\section{ORCID iDs}

Ezekiel Musa http://orcid.org/0000-0001-9995-8080

Tawanda Chivese http://orcid.org/0000-0001-6621-6144

\section{REFERENCES}

1 International Diabetes Federation. International diabetes Federation: IDF diabetes atlas. Brussels, Belgium, 2013.

2 Diagnostic criteria and classification of hyperglycaemia first detected in pregnancy: a world Health organization guideline. Diabetes Res Clin Pract 2014;103:341-63.

3 Albrecht SS, Kuklina EV, Bansil P, et al. Diabetes trends among delivery hospitalizations in the U.S., 1994-2004. Diabetes Care 2010;33:768-73.

4 Bell R, Bailey K, Cresswell T, et al. Trends in prevalence and outcomes of pregnancy in women with pre-existing type I and type II diabetes. BJOG 2008;115:445-52.

5 Feig DS, Hwee J, Shah BR, et al. Trends in incidence of diabetes in pregnancy and serious perinatal outcomes: a large, populationbased study in Ontario, Canada, 1996-2010. Diabetes Care 2014;37:1590-6.

6 Lawrence JM, Contreras R, Chen W, et al. Trends in the prevalence of preexisting diabetes and gestational diabetes mellitus among a racially/ethnically diverse population of pregnant women, 1999-2005. Diabetes Care 2008;31:899-904.

7 Chivese T, Werfalli MM, Magodoro I, et al. Prevalence of type 2 diabetes mellitus in women of childbearing age in Africa during 2000-2016: a systematic review and meta-analysis. BMJ Open 2019;9:e024345.

8 Muche AA, Olayemi OO, Gete YK. Prevalence and determinants of gestational diabetes mellitus in Africa based on the updated international diagnostic criteria: a systematic review and metaanalysis. Arch Public Health 2019;77:36.

9 Natamba BK, Namara AA, Nyirenda MJ, Burden NMJ. Burden, risk factors and maternal and offspring outcomes of gestational diabetes mellitus (GDM) in sub-Saharan Africa (SSA): a systematic review and meta-analysis. BMC Pregnancy Childbirth 2019;19:450.

10 Casson IF, Clarke CA, Howard CV, et al. Outcomes of pregnancy in insulin dependent diabetic women: results of a five year population cohort study. BMJ 1997;315:275-8.

11 Penney GC, Mair G, Pearson DWM. Outcomes of pregnancies in women with type 1 diabetes in Scotland: a national population-based study. BJOG: An Internal Journal of Obs Gyn 2003;110:315-8.

12 HAPO Study Cooperative Research Group, Metzger BE, Lowe LP, et al. Hyperglycemia and adverse pregnancy outcomes. $N$ Engl J Med 2008;358:1991-2002.

13 Wendland EM, Torloni MR, Falavigna M, et al. Gestational diabetes and pregnancy outcomes--a systematic review of the World Health Organization (WHO) and the International Association of Diabetes in Pregnancy Study Groups (IADPSG) diagnostic criteria. BMC Pregnancy Childbirth 2012;12:23.

14 Boney CM, Verma A, Tucker R, et al. Metabolic syndrome in childhood: association with birth weight, maternal obesity, and gestational diabetes mellitus. Pediatrics 2005;115:e290-6.

15 Damm P, Houshmand-Oeregaard A, Kelstrup L, et al. Gestational diabetes mellitus and long-term consequences for mother and offspring: a view from Denmark. Diabetologia 2016;59:1396-9.

16 Opara PI, Jaja T, Onubogu UC. Morbidity and mortality amongst infants of diabetic mothers admitted into a special care baby unit in Port Harcourt, Nigeria. Ital J Pediatr 2010;36:77.

17 Ekpebegh CO, Coetzee EJ, van der Merwe L, et al. A 10-year retrospective analysis of pregnancy outcome in pregestational type 2 diabetes: comparison of insulin and oral glucose-lowering agents. Diabet Med 2007;24:253-8.

18 Van Zyl H, Levitt NS. Pregnancy outcome in patients with pregestational and gestational diabetes attending Groote Schuur Hospital, Cape town, South Africa. S Afr Med J 2018;108:772-6.

19 Metzger BE, Gabbe SG, Persson B, et al. International association of diabetes and pregnancy study groups recommendations on the diagnosis and classification of hyperglycemia in pregnancy: response to Weinert. Diabetes Care 2010;33:e98-82.

20 American Diabetes Association. 2. Classification and Diagnosis of Diabetes: Standards of Medical Care in Diabetes-2018. Diabetes Care 2018;41:S13-27.

21 World Health Organization. Definition, diagnosis and classification of diabetes mellitus and its complications: report of a WHO consultation. Part 1, diagnosis and classification of diabetes mellitus, 1999.

22 World Health Organization. Diagnostic criteria and classification of hyperglycaemia first detected in pregnancy, 2013.

23 American College of Obstetricians and Gynecologists' Committee on Practice Bulletins-Obstetrics. Gestational hypertension and preeclampsia: ACOG practice Bulletin, number 222. Obstet Gynecol 2020;135:e237-60.

24 Tranquilli AL, Dekker G, Magee L, et al. The classification, diagnosis and management of the hypertensive disorders of pregnancy: a revised statement from the ISSHP. Pregnancy Hypertens 2014;4:97-104

25 Boyle A, Reddy UM, Landy HJ, et al. Primary cesarean delivery in the United States. Obstet Gynecol 2013;122:33-40.

26 Corsello G, Giuffrè M. Congenital malformations. J Matern Fetal Neonatal Med 2012;25(Suppl 1):25-9.

27 Regan L, Rai R. Epidemiology and the medical causes of miscarriage. Baillieres Best Pract Res Clin Obstet Gynaecol 2000;14:839-54.

28 World Health Organization. Neonatal and perinatal mortality: country regional and global estimates, 2006.

29 Goddijn M, Leschot NJ. Genetic aspects of miscarriage. Baillieres Best Pract Res Clin Obstet Gynaecol 2000;14:855-65.

30 Barfield WD, COMMITTEE ON FETUS AND NEWBORN. Standard terminology for fetal, infant, and perinatal deaths. Pediatrics 2016;137:e20160551.

31 Wyk Pavan VRR. Burden of disease review manager for systematic review of observational studies: technical report and user guide. Cape Town: South African Medical Research Council, 2018.

32 Hoy D, Brooks $P$, Woolf $A$, et al. Assessing risk of bias in prevalence studies: modification of an existing tool and evidence of interrater agreement. J Clin Epidemiol 2012;65:934-9.

33 Wells G, Shea B, O'connell D. The Newcastle-Ottawa scale (NOS) for assessing the quality of nonrandomised studies in meta-analyses, 2014. Ottawa Hospital Research Institute, 2015. 
34 Barendregt JJ, Doi SA, Lee YY, et al. Meta-analysis of prevalence. $J$ Epidemiol Community Health 2013;67:974-8.

35 DerSimonian R, Laird N. Meta-analysis in clinical trials. Control Clin Trials 1986;7:177-88.

36 Higgins JPT, Thompson SG, Deeks JJ. Measuring inconsistency in meta-analyses. BMJ 2003;327:557-60.

37 Egger M, Smith GD, Schneider M, et al. Bias in meta-analysis detected by a simple, graphical test. BMJ 1997;315:629-34.
38 Viera AJ, Garrett JM. Understanding interobserver agreement: the kappa statistic. Fam Med 2005;37:360-3.

39 Nyaga VN, Arbyn M, Aerts M. Metaprop: a Stata command to perform meta-analysis of binomial data. Arch Public Health 2014;72:39.

40 Stroup DF, Berlin JA, Morton SC. Meta-analysis of observational studies in epidemiology: a proposal for reporting. JAMA 2000;283:2008-12. 